\title{
Study on Hot Deformation Behavior of 7085 Aluminum Alloy during Backward Extrusion Process
}

\author{
R. B. Mei, ${ }^{1,2}$ Y. X. Du, ${ }^{2}$ L. Bao, ${ }^{1}$ X. Y. Zhang, ${ }^{1}$ B. Zhang, ${ }^{1}$ and Z. J. Zhou ${ }^{1}$ \\ ${ }^{1}$ Northeastern University at Qinhuangdao, Northeastern University, Qinhuangdao 066004, China \\ ${ }^{2}$ School of Materials and Metallurgy, Northeastern University, Shenyang 110819, China \\ Correspondence should be addressed to R. B. Mei; meirbbaol@126.com
}

Received 15 November 2014; Revised 1 March 2015; Accepted 12 March 2015

Academic Editor: Antonio Munjiza

Copyright (c) 2015 R. B. Mei et al. This is an open access article distributed under the Creative Commons Attribution License, which permits unrestricted use, distribution, and reproduction in any medium, provided the original work is properly cited.

\begin{abstract}
Compression test was carried out and the true stress-strain curves were obtained from the hot compression of 7085 alloy. A numerical simulation on the deformation behavior of 7085 aluminum alloy during the backward extrusion was also performed by finite element method. The results show that dynamic recrystallization occurs in the hot compression of 7085 alloy and the peak stress reaches higher values as the strain rate increases and deformation temperature decreases. The backward extrusion processes include contact deformation, initial deformation, and steady deformation. Severe plastic deformation of shear and compression occurs when the metal flowed into the channel between fillet of punch and wall of die so that the grain size can be refined by backward extrusion. The deformation in the region of top of wall is too small to meet the mechanical properties of requirements and the metal usually needs to be trimmed. The experiments with the same parameters as simulation had been carried out and the experimental cup after extrusion has better quality.
\end{abstract}

\section{Introduction}

The backward extrusion method has been successfully utilized as a final processing route to generate fine-grained products $[1,2]$. Consequently this method has become one of the most promising manufacturing processes due to its material savings, proper stress distributions, and lower required machining. Aluminum alloys have been the most widely used structural materials in aeronautics and aerospace industry and two types of alloys make up the bulk of the wrought aluminum found in modern aircraft including 2000 series $(\mathrm{Al}-\mathrm{Cu}-\mathrm{Mg}$ ) and 7000 series $(\mathrm{Al}-\mathrm{Zn}-\mathrm{Mg}-\mathrm{Cu})$ alloys [3] . 7085 alloys have some advantageous properties that make them excellent choice for application in aerospace component manufacturing [4]. However, 7085 alloy has bad ability of plastic deformation at lower temperature so that hot forming is the main processing technology. In order to exploit the benefits of the alloy, it is essential to investigate the hot deformation behavior and optimize the processing parameters. With the development of computer-hardware and numerical processing technology, numerical simulation has been proven to be the most accurate method to study the heat transfer, deformation behavior, or dynamic recrystallization (DRX) process during backward extrusion processing. Mei et al. $[5,6]$ used DEFORM 3D to develop program and discuss the dynamic recrystallization, grain size, stress/strain distribution, and forming load of different alloy during hot backward extrusion. Ketabchi et al. [7] carried out an experimental and finite element analysis of a backward extrusion process of $7075 \mathrm{Al}$ alloy and studied subsequently the forming load and distribution of strain and stress. Fatemi-Varzaneh et al. [8] proposed a cyclic backward extrusion method to obtain ultra-fine-grained materials and the distribution of strain and stress was predicted by ABAQUS software. A homogenous equivalent plastic strain is gained after applying a single pass accumulative back extrusion, whereas the normal strain was distributed inhomogeneously. However, there are few reports on the deformation behavior of 7085 alloy in the hot backward extrusion processes.

The present work has been conducted to investigate the hot deformation behavior based on the compress tests. The stress-strain curves of 7085 aluminum alloy at higher 


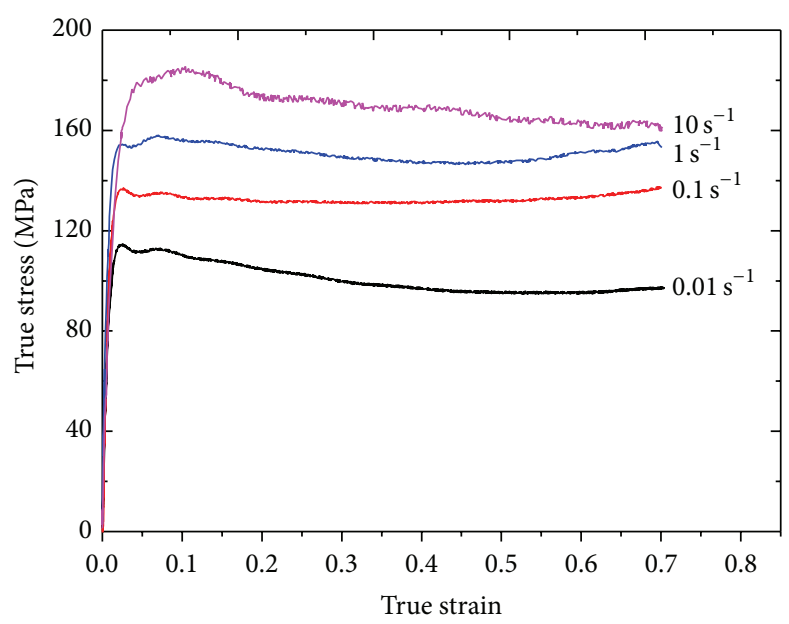

(a)

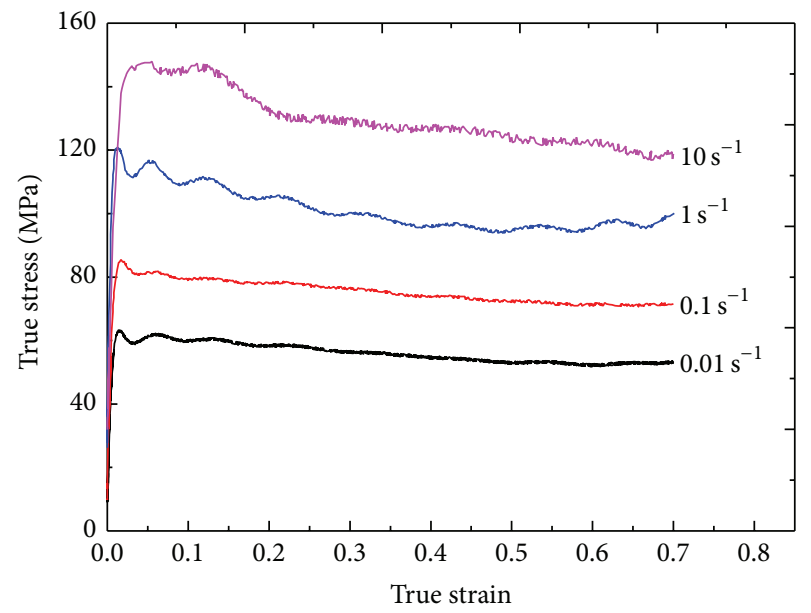

(c)

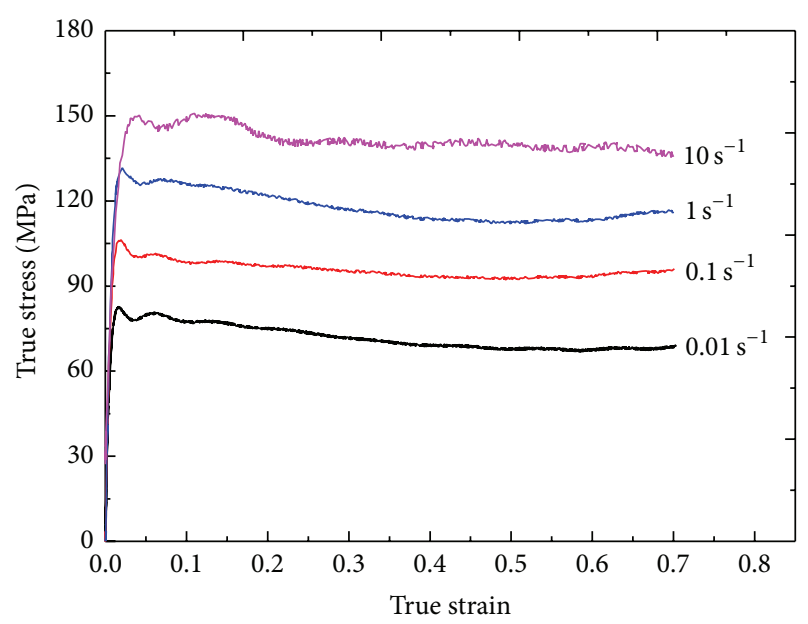

(b)

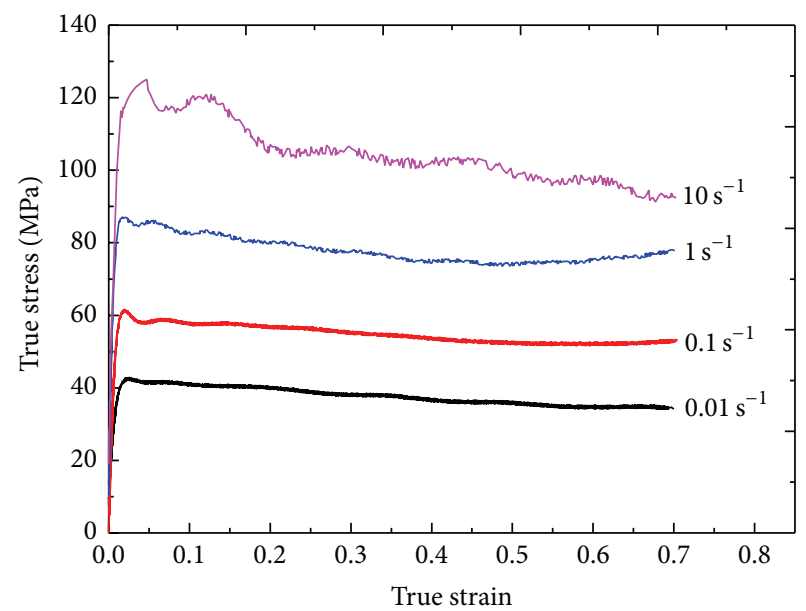

(d)

Figure 1: Flow stress-strain curves with (a) $300^{\circ} \mathrm{C}$; (b) $350^{\circ} \mathrm{C}$; (c) $400^{\circ} \mathrm{C}$; (d) $450^{\circ} \mathrm{C}$.

temperature were obtained through compress tests firstly. Then a numerical simulation and an experiment on backward extrusion processing were performed on the basis of stressstrain equation and finite element method. Furthermore, the distribution of stress/strain and forming load had been investigated to describe the hot deformation mechanism.

\section{Simulation Conditions}

2.1. FE Formulation. In this section, the rigid-plastic finite element formulation is briefly described. The penalty function method in rigid-plastic FEM has been employed to many forming problems. According to variation principle, the real velocity field must minimize the following functional [9]:

$$
\pi=\int_{V} \bar{\sigma} \dot{\varepsilon} d V+\frac{K}{2} \int_{V}\left(\dot{\varepsilon}_{v}\right)^{2} d V-\int_{S_{F}} F_{i} u_{i} d S=0
$$

where $\bar{\sigma}$ is the equivalent stress, $\dot{\varepsilon}$ is the equivalent strain rate, $K$ is the penalty constant, $\dot{\varepsilon}_{v}$ is the volume strain, $F_{i}$ is the external force on the force surface $s_{F}, u_{i}$ is the velocity vector, and $V$ is the volume of the deformation body.
Because the plastic deformation is a nonlinear transient heat transient heat transfer process, the temperature distribution of the die or workpiece in the analysis of heat-transfer can be obtained by solving the energy balance equation

$$
\nabla\left(k_{i} \nabla T\right)+Q=\rho c \frac{\partial T}{\partial t},
$$

where $T$ is absolute temperature $(\mathrm{K}), \rho$ is density $\left(\mathrm{kg} / \mathrm{m}^{3}\right)$, $c$ is specific heat $(\mathrm{J} /(\mathrm{kg} \cdot \mathrm{K})), t$ is time $(\mathrm{s}), k_{i}$ is conductivity coefficient in $x, y$, and $z$ direction $(\mathrm{W} /(\mathrm{m} \cdot \mathrm{K}))$, and $Q$ is heat generated due to plastic work and friction $(\mathrm{W} / \mathrm{kg})$.

2.2. Material Equation. A commercial 7085 aluminum alloy of compositions (wt\%): $0.03 \mathrm{Si}-0.08 \mathrm{Fe}-1.30 \mathrm{Cu}-0.03 \mathrm{Mn}$ $1.4 \mathrm{Mg}-0.03 \mathrm{Cr}-7.16 \mathrm{Zn}$ was used in this investigation. Cylindrical samples with $10 \mathrm{~mm}$ in diameter and $15 \mathrm{~mm}$ in height were machined. Compression tests were carried out on a computer servo-controlled MMS-300 system with strain of 0.65 , strain rate of $0.01 \mathrm{~s}^{-1}, 0.1 \mathrm{~s}^{-1}, 1 \mathrm{~s}^{-1}$, and $10 \mathrm{~s}^{-1}$, and deformation temperature of $300^{\circ} \mathrm{C}, 350^{\circ} \mathrm{C}, 400^{\circ} \mathrm{C}$, and $450^{\circ} \mathrm{C}$. The samples 


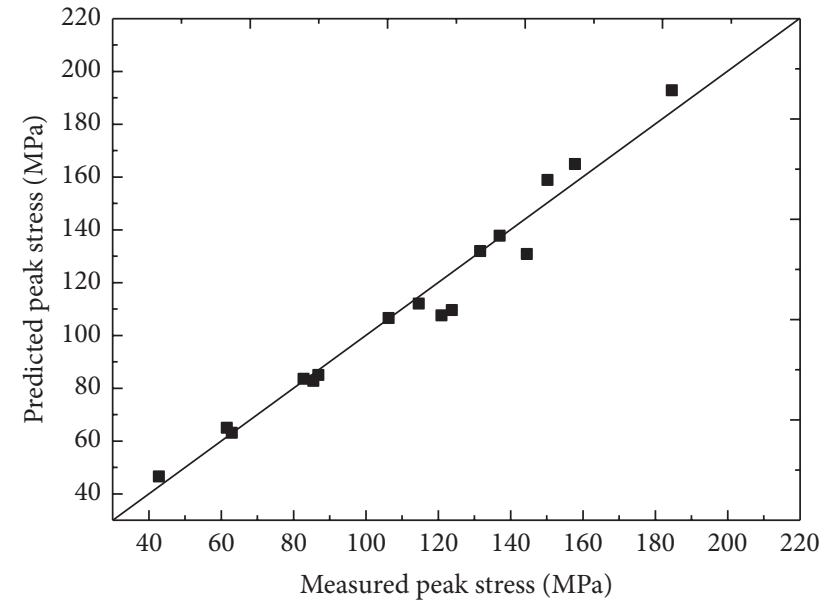

Figure 2: A comparison between predicted and measured peak stress with different temperature and strain rate.

are resistance heated to deformation temperature at a heating rate of $10^{\circ} \mathrm{C} / \mathrm{s}$ and held at deformation temperature for 2 minutes before compression. Examples of the true stressstrain curves obtained from the hot compression of 7085 alloy are depicted in Figure 1. It can be seen that the influence of the temperature, strain, and strain rate on the flow stress is significant. Under a certain temperature and strain rate, the true stress firstly increases to peak value and then keeps a stable level. The dislocation density increases significantly resulting in an increased resistance of dislocation movement. Therefore, work hardening with dislocation density rise is the dominant position. However, the deformation distortion provides driving force for dynamic recrystallization or recovery softening with the continuous increase of dislocation density. When the softening rate is faster than hardening rate the stress decreases and tends to a stable value. It is also found that dynamic recrystallization occurs in the hot compression of 7085 alloy. Furthermore, the peak stress reaches higher values as the strain rate increases and deformation temperature decreases.

The constitutive equation had been modeled according to the true stress-strain curves obtained. The constitutive models for peak stress of extruded 7085 alloy under hot deformation can be summed as the following equations on the basis of Arrhenius equation and Zener-Hollomon parameter [10-13]:

$$
\begin{array}{r}
\sigma=87.28 \ln \left\{\left(\frac{Z}{4.8 \times 10^{11}}\right)^{1 / 6.945}\right. \\
\left.+\left[\left(\frac{Z}{4.8 \times 10^{11}}\right)^{2 / 6.945}+1\right]^{1 / 2}\right\}, \\
Z=\dot{\varepsilon} \exp \left[\frac{166957}{(\mathrm{RT})}\right] .
\end{array}
$$

Figure 2 shows the comparison between the predicted peak stress and experimental data. It can be seen that the predicted values are in good agreement with the measured
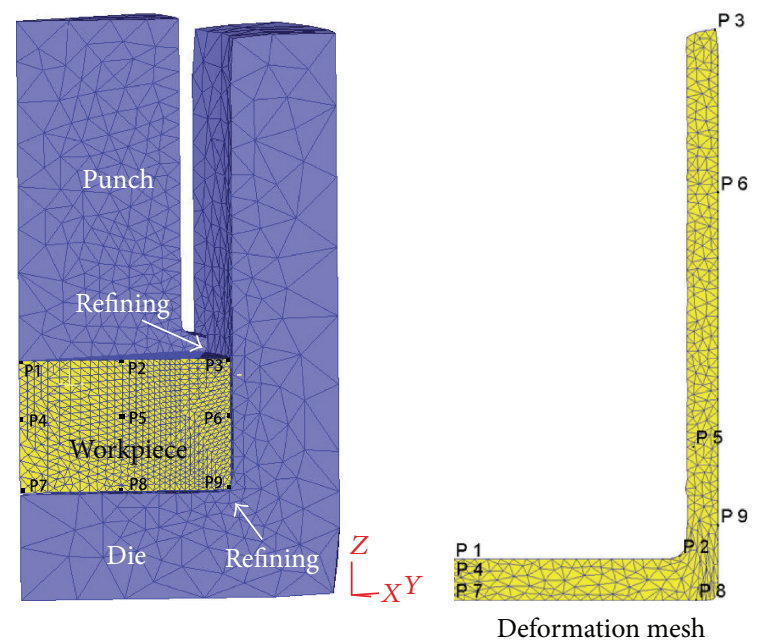

Figure 3: Mesh before and after deformation.

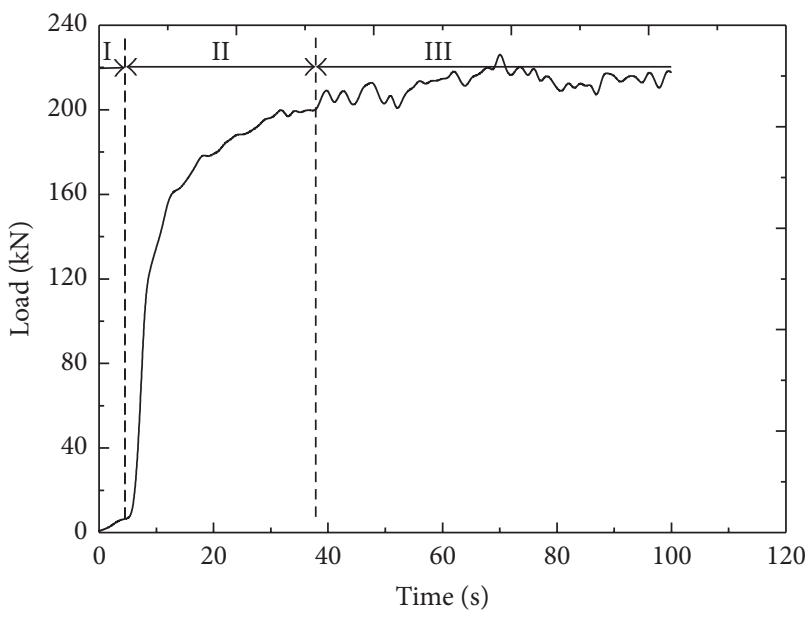

FIGURE 4: Load-time curves with deformation.

value and the maximum error is less than $11.47 \%$. Therefore, the material model for the FE analysis of 7085 alloy during backward extrusion is reliable.

2.3. Mesh Model and Parameters. A twelfth workpiece is used to solve and analyze the backward extrusion processes because the cylindrical cup, punch, and bottom die are axisymmetric. The initial and finial FE meshes are shown in Figure 3. In addition, the mesh in the corner of die is refined and the remeshing method is carried out in order to improve the precision. The total numbers of elements and nodes of workpiece are 23142 and 5039, respectively. It can be seen from the mesh (Figure 3 ) before and after backward extrusion that the deformation of features points P1, P4, and $\mathrm{P} 7$ is compression in axial direction. The deformation of P2, P8, and P9 is mainly in axial and radial direction. The maximum plastic deformation is $\mathrm{P} 5$ compared with the other points according to the position of metal flow before and after deformation. The metal flows into the wall of cup directly so 


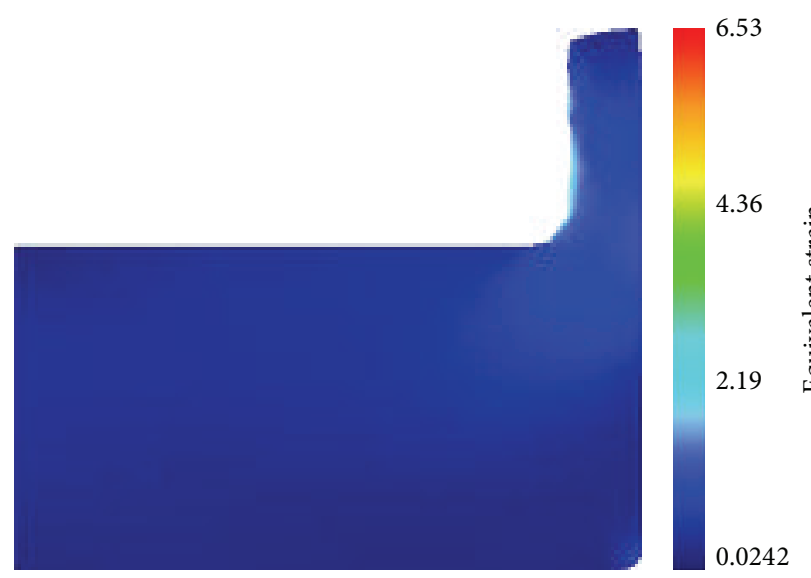

(a)

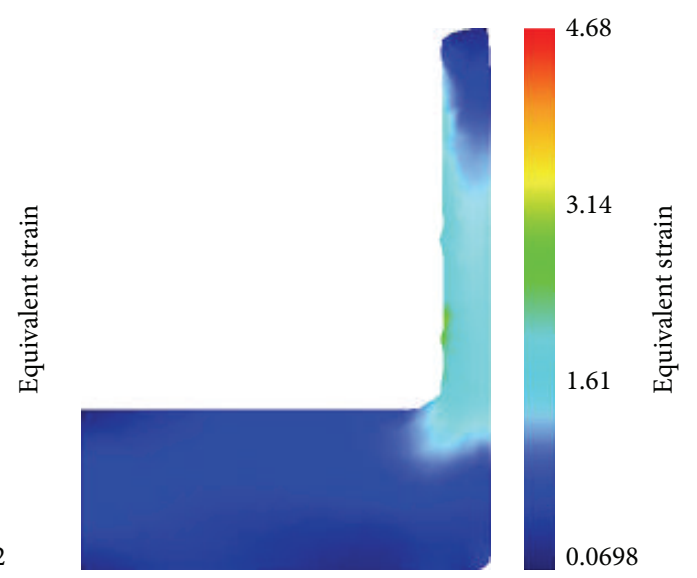

(b)

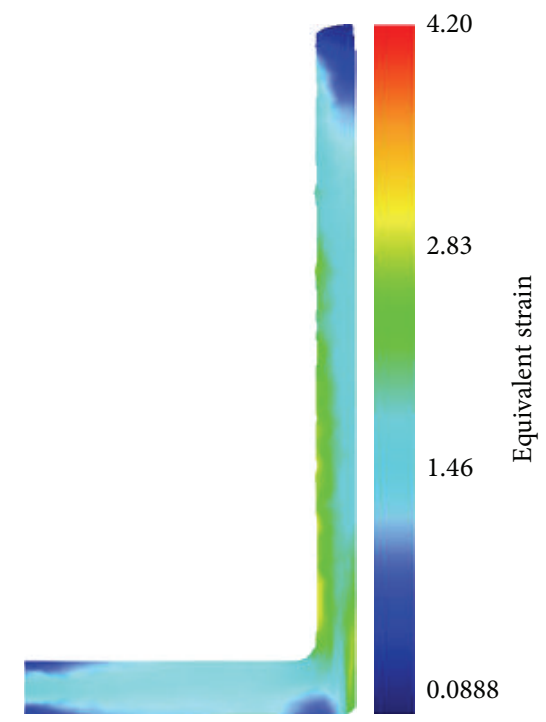

(c)

FIGURE 5: Equivalent strain contours with different deformation: (a) $\Delta h=5 \mathrm{~mm}$; (b) $\Delta h=10 \mathrm{~mm}$; (c) $\Delta h=20 \mathrm{~mm}$.

that the minimum values of deformation are P3 and P6 after deformation.

The simulated parameters are as follows: the initial temperature of workpiece is set to $400^{\circ} \mathrm{C}$, the speeds of punch are $1 \mathrm{~mm} / \mathrm{s}$, the preheating temperature of die is $100^{\circ} \mathrm{C}$, the friction factor is 0.4 , and the fillet of punch is $1.5 \mathrm{~mm}$. Furthermore, the initial size of workpiece is $\Phi 80(\mathrm{~mm}) \times$ $25(\mathrm{~mm})$ and the reduction is $20(\mathrm{~mm})$.

\section{Results and Discussion}

The load-time curve is shown in Figure 4. It can be seen that the deformation processes include contact deformation, initial deformation, and steady deformation. In the first stage, the workpiece is contacted with the punch and die completely and the load increases slowly. With the movement of punch, the resistance and work hardening result in increasing the deformation load significantly. In the steady deformation stage, the occurrence of dynamic recovery and recrystallization leads to the balance between softening and work hardening process. The average forming load is about $205 \mathrm{kN}$ at the steady deformation stage.

The distribution of equivalent strain contours with different deformation is shown in Figure 5. As is seen, the results are presented in two dimensions and the dies and guides are not included. It can be seen that the regions along the top areas of workpiece are severely deformed. The distribution of equivalent strain is inhomogeneous in the early stages of deformation and the maximum value of equivalent strain lies in the corner of punch. The maximum value of equivalent strain decreases with the increment of deformation so that the deformation goes to be more homogenized. Furthermore, it is found obviously that there are four regions with smaller deformation occurring from the contour of last stages. The metal in the outside of top of workpiece with smaller deforming results in the less equivalent strain and poorer mechanical properties at the top of sample wall after backward extrusion. The metal flow is hindered by the wall of die which leads to the equivalent strain in regions 


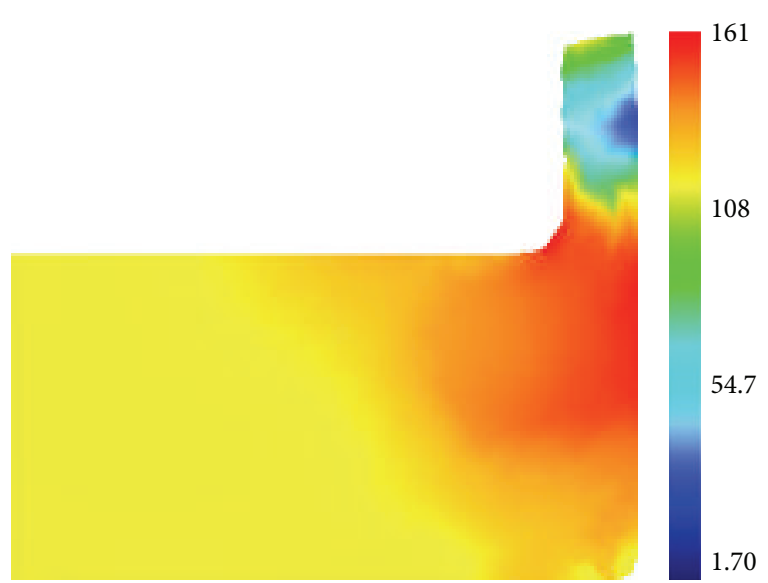

(a)

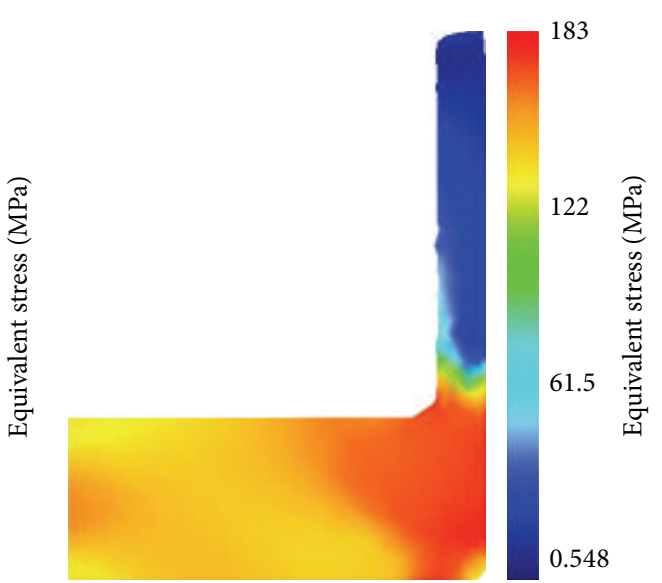

(b)

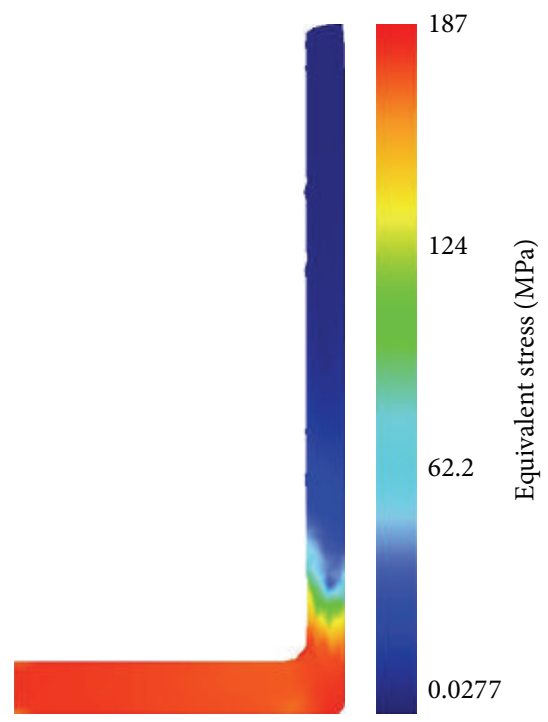

(c)

FIGURE 6: Equivalent stress contours with different deformation: (a) $\Delta h=5 \mathrm{~mm}$; (b) $\Delta h=10 \mathrm{~mm}$; (c) $\Delta h=20 \mathrm{~mm}$.

close to the die bottom and wall which is also lower in comparison to the other areas. In addition, the metal in the center of top and bottom of workpiece has less deformation and lower equivalent strain because of friction. In a word, larger equivalent strain which occurred in the backward extrusion is beneficial to improve the mechanical properties but the deformation is not completely homogenous because of friction and characteristics of deformation.

Figure 6 shows the distribution of equivalent stress with different deformation. It can be seen that the maximum value of equivalent stress lies in the channel between corner of punch and the wall of die. With the movement of punch, the equivalent stress increases and the maximum value is $161 \mathrm{MPa}$ and $187 \mathrm{MPa}$ with $\Delta h=5 \mathrm{~mm}$ and $\Delta h=20 \mathrm{~mm}$, respectively. The equivalent stress becomes less when the metal flows into wall and the minimum value decreases with the deformation.

The distribution of max shear stress contour with different deformation is shown in Figure 7. It is found that the max shear stress has the same distribution as the equivalent stress. Severe shear plastic deformation in the channel of punch and wall of bottom die can refine the grain size. The regions of shear stress increase firstly and then decrease but the maximum shear stress increases during the backward extrusion. The maximum value of max shear stress is $105 \mathrm{MPa}$ and $107 \mathrm{MPa}$, respectively, with reduction $5 \mathrm{~mm}$ and $20 \mathrm{~mm}$.

The equivalent strain, equivalent stress, and mean stress of typical point with different deformation are shown in Figure 8. It can be seen that the equivalent strain of all points but points 3 and 6 increases with the deformation. The equivalent strain of points 3 and 6 increases firstly and then keeps a stable value when the metal flows into the channel between punch and wall of die. However, the value of equivalent strain for the other points increases higher with increment of reduction. It can be seen from the equivalent stress that the equivalent stress of points 3 and 6 increases firstly in the initial deformation stage and then significantly 


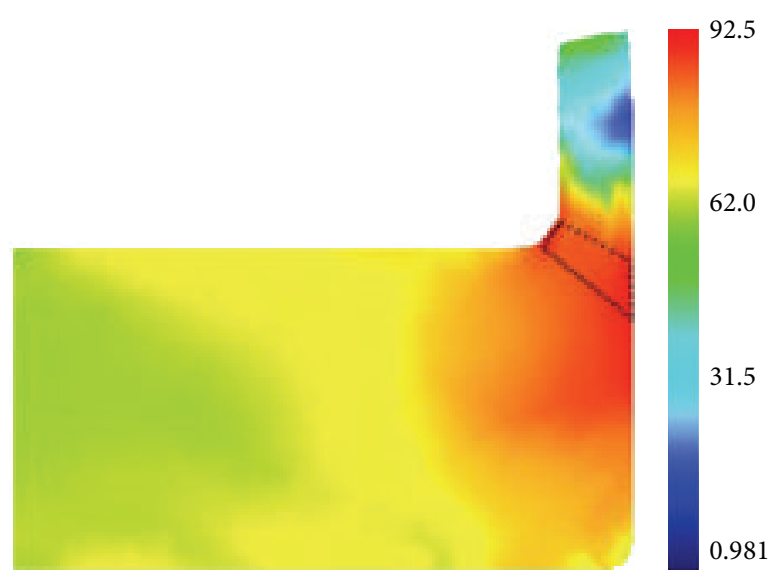

(a)

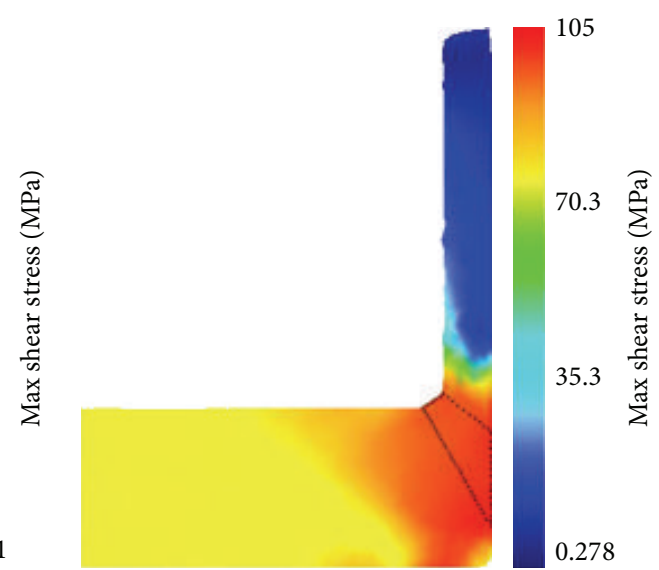

(b)

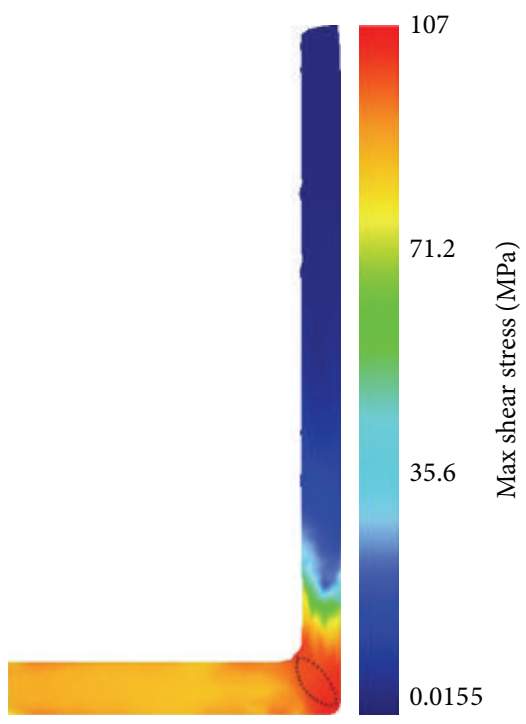

(c)

FIGURE 7: Max shear stress contours with different deformation: (a) $\Delta h=5 \mathrm{~mm}$; (b) $\Delta h=10 \mathrm{~mm}$; (c) $\Delta h=20 \mathrm{~mm}$.

decreases to be stable steady compared with those of the other points. From the mean stress the absolute mean stress decreases significantly when the metal flows into the channel between punch and die. Only compressible deformation results in higher hydrostatic pressure for point 1 , point 4 , and point 7 but the lower absolute mean stress occurring in point 3 and point 6 results from the lesser effect of friction and deformation. The mean stress of most of the points is less than zero so that the three-axial compressible stress state of backward extrusion is beneficial to severe plastic deformation.

The experiments have been carried out with the deformation temperature $400^{\circ} \mathrm{C}$, deformation speed $1 \mathrm{~mm} / \mathrm{s}$, and the preheat temperature of die $120^{\circ} \mathrm{C}$. The experimental and predicted cylindrical cup samples are also obtained and shown in Figure 9. It can be seen that the mesh after deformation is fine and the experimental sample has better surface quality which can meet the production requirement.

\section{Conclusions}

(1) Compression tests were carried out and the true stressstrain curves were obtained from the hot compression of 7085 alloy. Under a certain temperature and strain rate, the true stress firstly increases to peak value and then keeps a stable level. Furthermore, dynamic recrystallization occurs in the hot compression of 7085 alloy and the peak stress reaches higher values as the strain rate increases and deformation temperature decreases.

(2) The backward extrusion processes include contact deformation, initial deformation, and steady deformation. In the steady deformation stage, the occurrence of dynamic recovery and recrystallization leads to the balance between softening and work hardening process.

(3) Severe plastic deformation of shear and compression occurs when the metal flowing through the channel between fillet of punch and wall of die occurs so that the grain size 


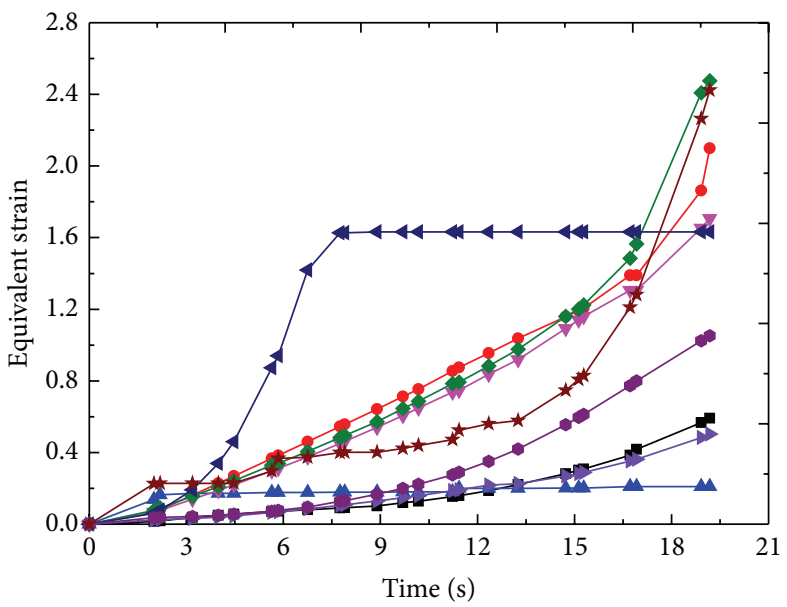

(a)

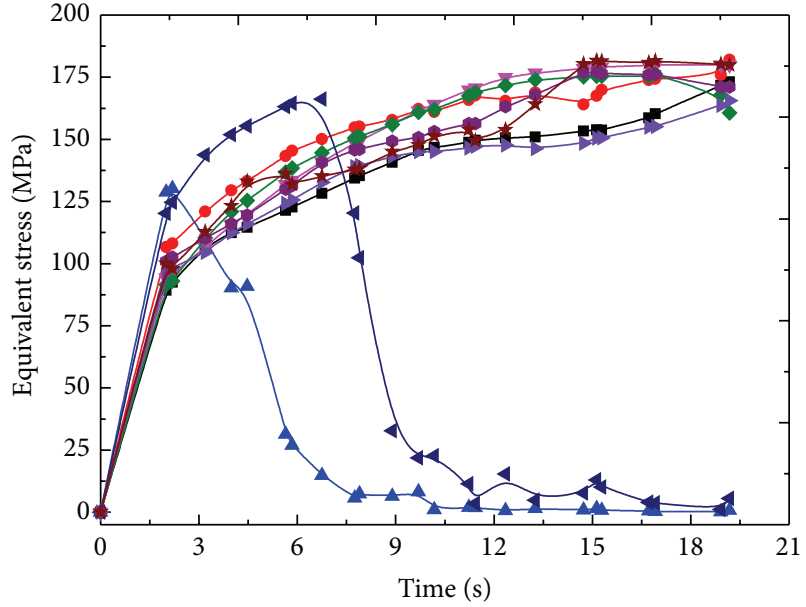

(b)

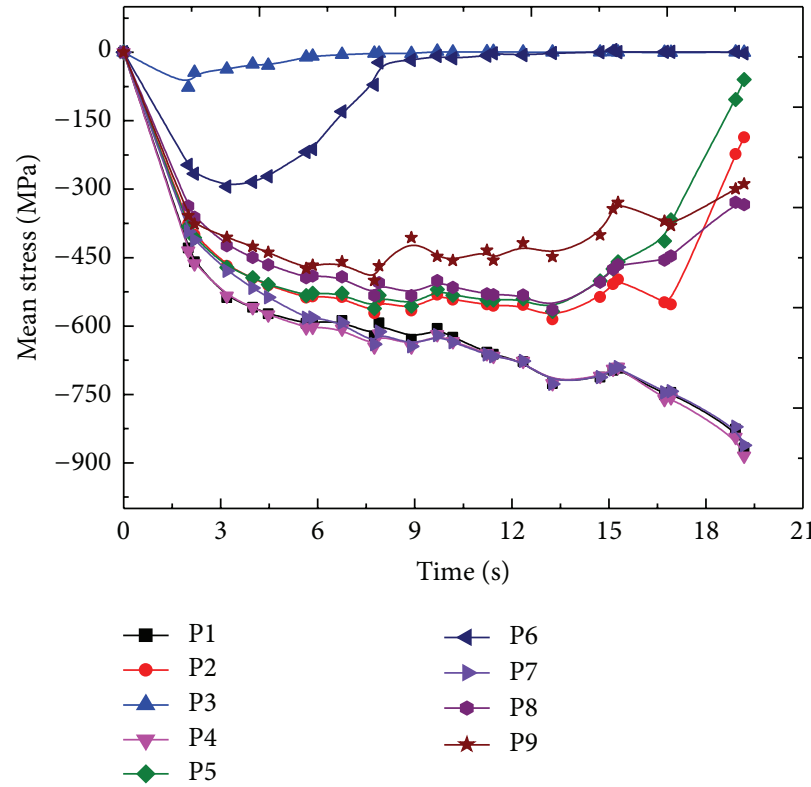

(c)

FIGURE 8: Change of equivalent strain, equivalent stress, and mean stress of typical point with time: (a) equivalent strain; (b) equivalent stress; (c) mean stress.

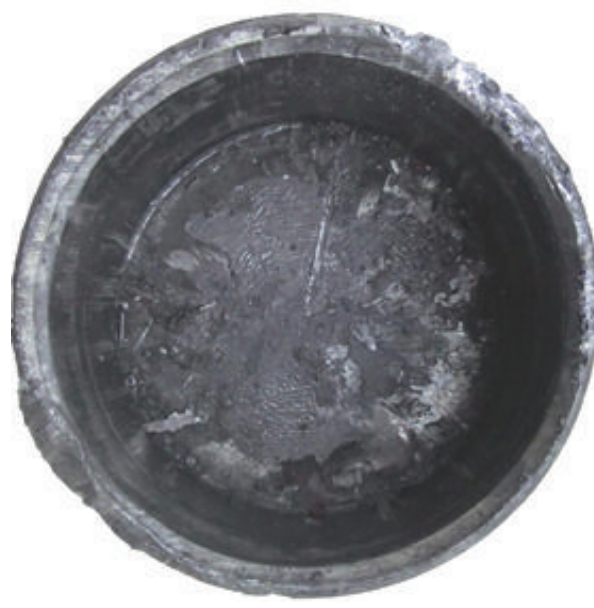

(a)

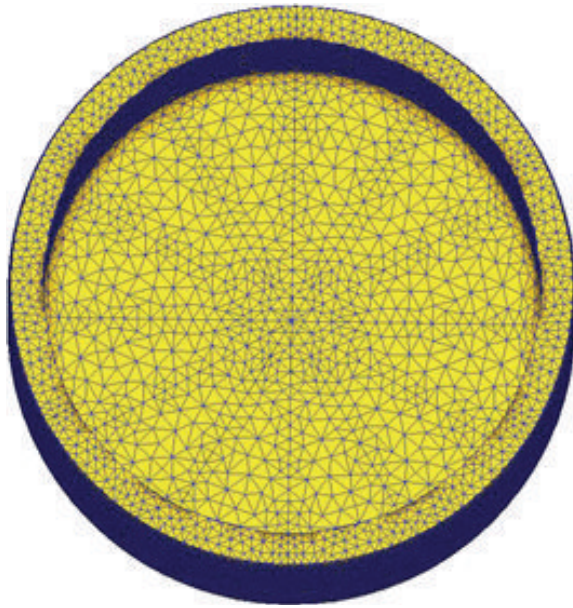

(b)

FIGURE 9: Cylindrical cup: (a) experimental sample; (b) predicted sample. 
can be refined by backward extrusion. In the early stages, the deformation is nonuniform and the inhomogeneous deformation is improved with the increment of reduction. However, the final deformation is inhomogeneous because of friction and metal flow difference.

(4) The maximum shear stress and equivalent stress occur in the channel between punch and die and the value increases with the increment of reduction. The experiments with the same parameters as simulation have been carried out and the experimental cup after extrusion has better quality which can meet with the production requirement.

\section{Conflict of Interests}

The authors declare that there is no conflict of interests regarding the publication of this paper.

\section{Acknowledgments}

The authors gratefully acknowledge the financial support from the Natural Science Foundation-Steel and Iron Foundation of Hebei Province (no. E2014501114), the Science and Technological Youth Foundation of Hebei Higher Education (no. 20132007), and the Qinhuangdao Technology Support Project (no. 2012021A105).

\section{References}

[1] Q. Peng, H. Dong, Y. Tian, and H. Zhang, "Effect of backward extrusion on microstructure and mechanical properties of $\mathrm{Mg}-$ Gd based alloy," Materials Science and Engineering A, vol. 532, pp. 443-448, 2012.

[2] H. Alihosseini, M. Asle Zaeem, and K. Dehghani, "A cyclic forward-backward extrusion process as a novel severe plastic deformation for production of ultrafine grains materials," Materials Letters, vol. 68, pp. 204-208, 2012.

[3] Y. Wang and Z. Jiang, "Dynamic compressive behavior of selected aluminum alloy at low temperature," Materials Science and Engineering A, vol. 553, pp. 176-180, 2012.

[4] S. L. Dai, K. Zhang, S. J. Yang et al., Advanced Aeronautical Aluminum Alloy Materials Technology and Application, National Defense Industry Press, Beijing, China, 2012.

[5] X. B. Wang, R. B. Mei, Y. Fan et al., "Deformation analysis of TC6 titanium alloy cylinder in backward extrusion," Hot Working Technology, vol. 42, pp. 5-9, 2013.

[6] X. Hu, R. B. Mei, F. Zhu et al., "Numerical simulation for microstructure evolution in IN718 alloy during cylindrical cup backward extrusion," Advanced Materials Research, vol. 650, pp. 92-97, 2013.

[7] M. Ketabchi, H. Mohammadi, and M. Izadi, "Finite-element simulation and experimental investigation of Isothermal backward extrusion of $7075 \mathrm{Al}$ alloy," Arabian Journal for Science and Engineering, vol. 37, no. 8, pp. 2287-2296, 2012.

[8] S. M. Fatemi-Varzaneh, A. Zarei-Hanzaki, M. Naderi, and A. A. Roostaei, "Deformation homogeneity in accumulative back extrusion processing of AZ31 magnesium alloy," Journal of Alloys and Compounds, vol. 507, no. 1, pp. 207-214, 2010.

[9] S. Kobayashi, S. I. Oh, and T. Altan, Metal Forming and the Finite Element Method, Oxford University Press, New York, NY, USA, 1989.
[10] C. M. Sellars and W. J. McTegart, "On the mechanism of hot deformation," Acta Metallurgica, vol. 14, no. 9, pp. 1136-1138, 1966.

[11] H. J. McQueen and N. D. Ryan, "Constitutive analysis in hot working," Materials Science and Engineering A, vol. 322, no. 1-2, pp. 43-63, 2002.

[12] G.-Z. Quan, Y.-P. Mao, G.-S. Li, W.-Q. Lv, Y. Wang, and J. Zhou, "A characterization for the dynamic recrystallization kinetics of as-extruded 7075 aluminum alloy based on true stress-strain curves," Computational Materials Science, vol. 55, pp. 65-72, 2012.

[13] J. H. Guo, S. D. Zhao, R.-I. Murakami, R. Ding, and S. Fan, "Modeling the hot deformation behavior of Al alloy 3003," Journal of Alloys and Compounds, vol. 566, pp. 62-67, 2013. 

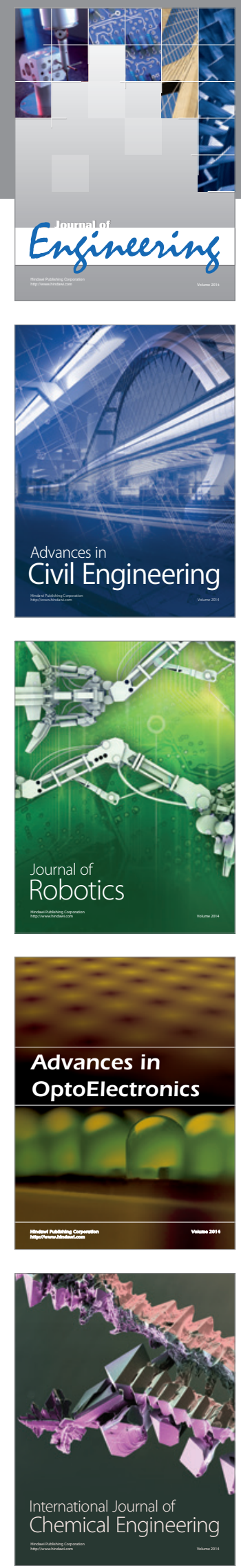

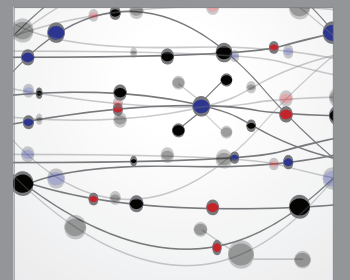

The Scientific World Journal
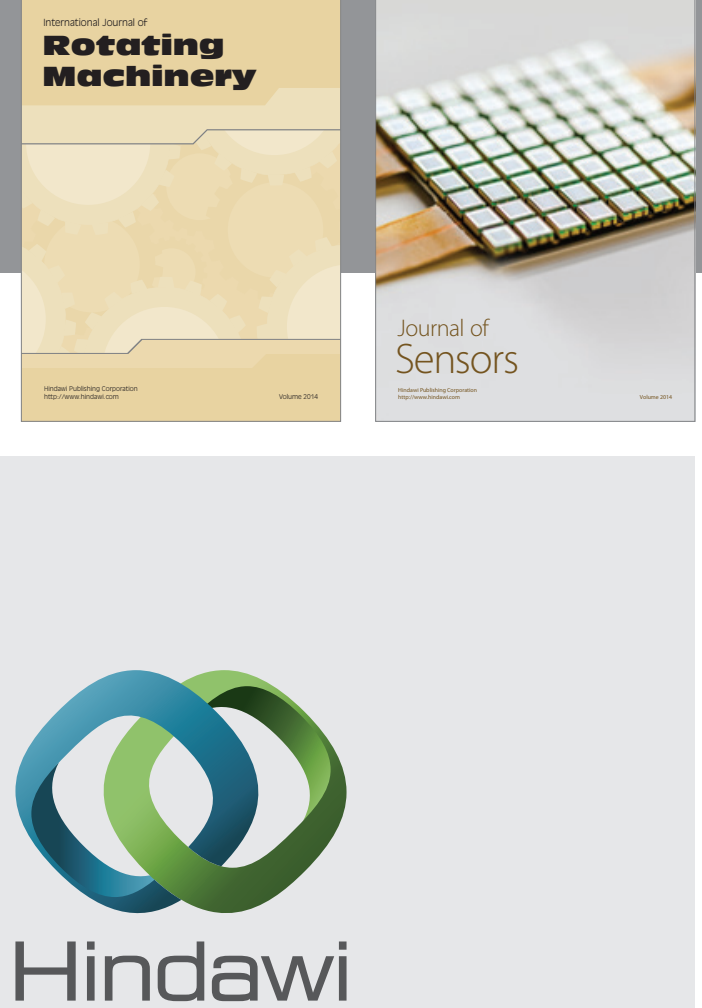

Submit your manuscripts at http://www.hindawi.com
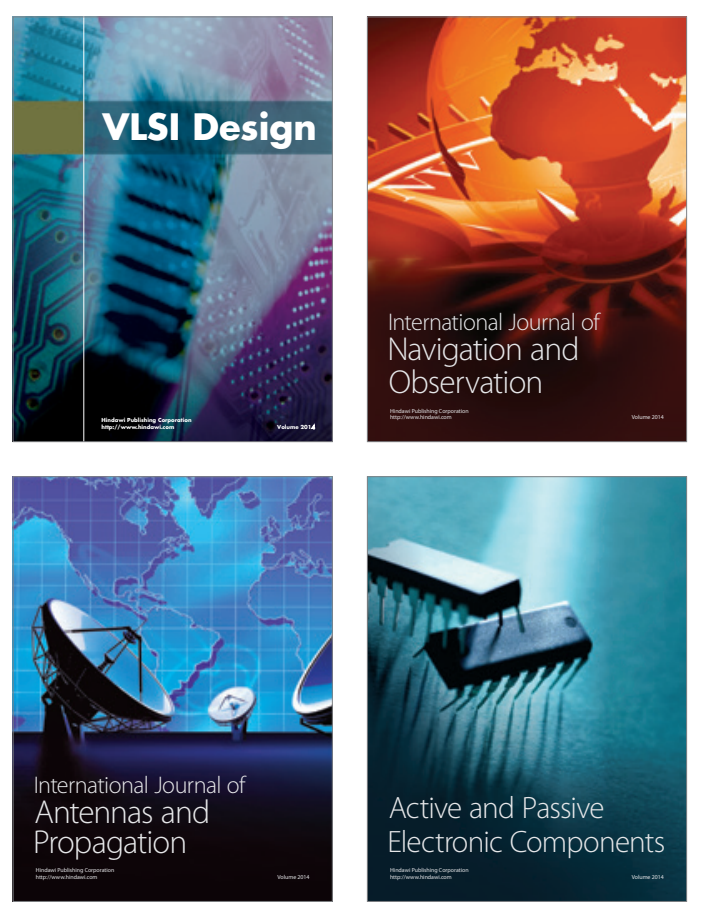
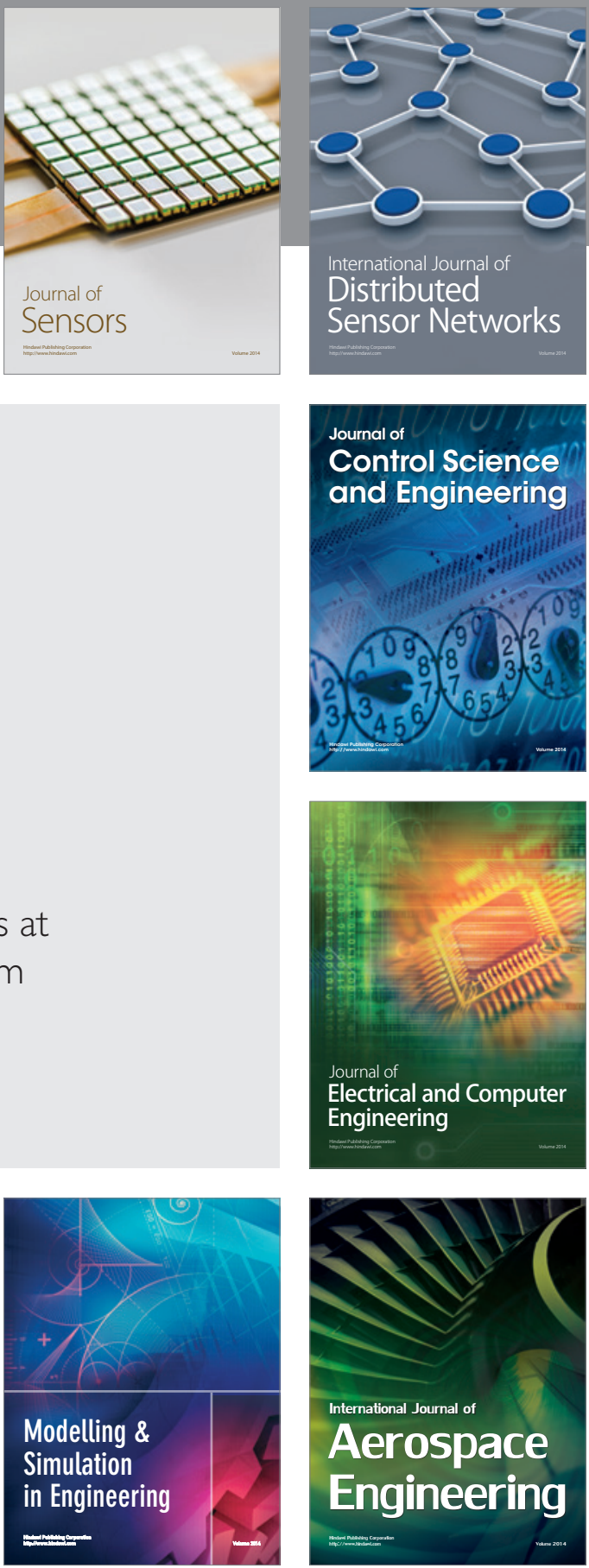

Journal of

Control Science

and Engineering
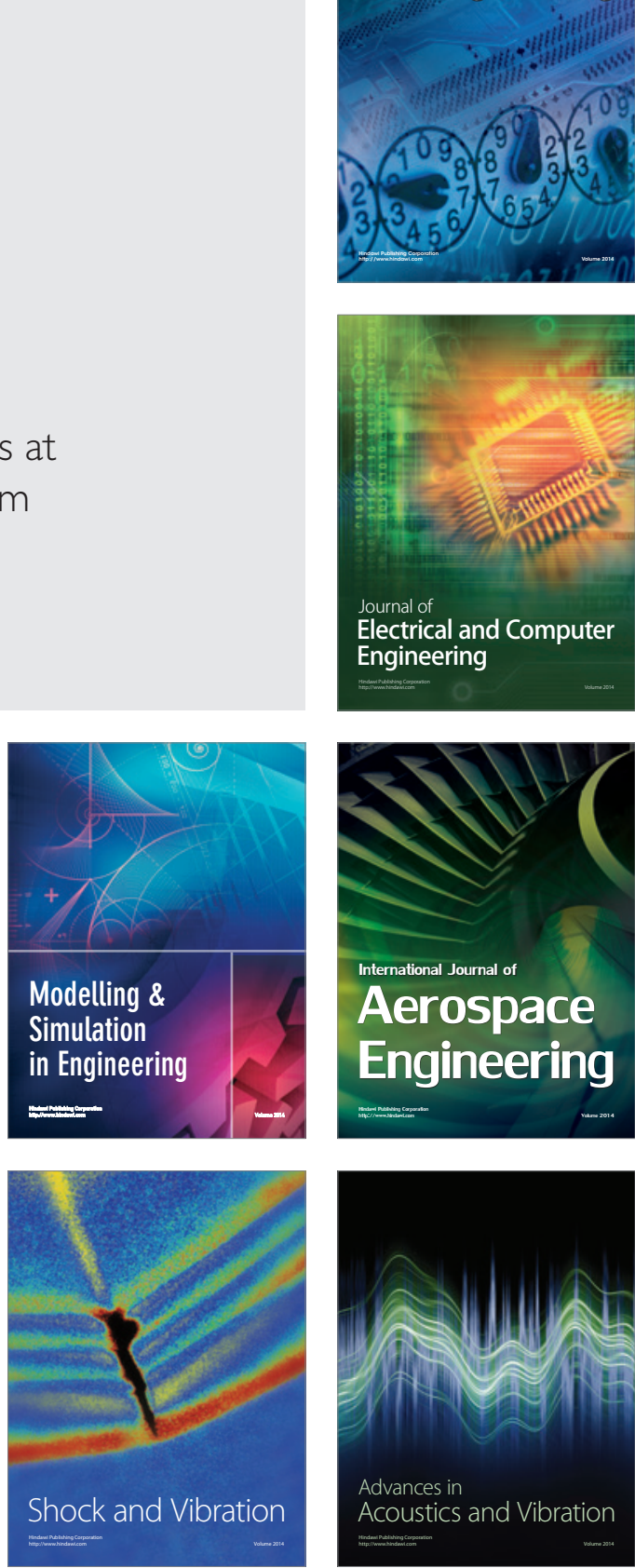